\title{
EVAPOTRANSPIRAÇÃO DE REFERÊNCIA MENSAL E ANUAL PELO MÉTODO DE THORNTHWAITE PARA O ESTADO DA PARAÍBA
}

\author{
FRANCISCO, Paulo Roberto Megna - paulomegna@gmail.com \\ Universidade Federal da Paraíba / UFPB
}
MEDEIROS, Raimundo Mainar de - mainarmedeiros@gmail.com Universidade Federal de Campina Grande / UFCG
MATOS, Rigoberto Moreira de - rigobertomoreira@gmail.com Universidade Federal de Campina Grande / UFCG
SANTOS, Djail Santos - santosdj@cca.ufpb.br Universidade Federal da Paraíba - UFPB
SABOYA, Luciano Marcelo Falle - saboya@deag.ufcg.edu.br Universidade Federal de Campina Grande / UFCG

\begin{abstract}
RESUMO: Evapotranspiração terrestre é um dos componentes mais importantes do ciclo hidrológico, afetando o equilíbrio da água na superfície da Terra. Teve-se como objetivo estimar e avaliar a variação da evapotranspiração de referência e suas flutuações espaço-temporal mensal, anual e os trimestres menos e mais evaporativo no Estado da Paraíba, utilizando-se o método empírico de Thornthwaite. Com base nas equações de estimativa da temperatura média do ar estimou-se a ETo para os 223 municípios gerando-se planilhas mensais e anuais. Os resultados demonstraram que as estimativas de ETo mensais para o Estado da Paraíba apresentaram dependência da localização geográfica, sobretudo, da topografia local; os resultados estão de acordo com vários estudos realizados para a região semiárida do Nordeste Brasileiro; esta tendência é um reflexo da variação espacial da temperatura média o ar mensal na área de estudo; em todos os meses do ano as regiões do Litoral, Brejo e Sertão demandaram as maiores taxas evapotranspiratórias e as menores taxas ocorreram no Agreste, Cariri/Curimataú e Alto Sertão.
\end{abstract}

Palavras- chaves: Planejamento Agrícola, Balanço hídrico, Demanda Hídrica, Irrigação.

\section{REFERENCE EVAPOTRANSPIRATION MONTHLY AND ANNUAL BY THORNTHWAITE METHOD FOR THE STATE OF PARAÍBA}

\begin{abstract}
Terrestrial evapotranspiration is one of the most important components of the hydrological cycle, affecting the balance of water on the Earth's surface. The objective of this study was to estimate and evaluate the variation of the reference evapotranspiration and its monthly, annual and seasonal space-time fluctuations and the less and more evaporative quarters in the state of Paraíba, using the Thornthwaite empirical method. Based on the estimation equations of the mean air temperature, ETo was estimated for the 223 municipalities, generating monthly and annual spreadsheets. The results showed that the estimates of ETo monthly for the State of Paraíba showed dependence of the geographical location, mainly of the local topography; The results are in agreement with several studies carried out for the semiarid region of Northeast Brazil; This trend is a reflection of the spatial variation of the mean air temperature in the monthly area of study; In all the months of the year the Litoral, Brejo and Sertão regions demanded the highest evapotranspiration rates and the lowest rates occurred in Agreste, Cariri / Curimataú and Alto Sertão.
\end{abstract}

Keys- words: Agricultural Planning, Water Balance, Water Demand, Irrigation. 


\section{INTRODUÇÃO}

A agricultura é uma atividade econômica que por estar sujeita à variabilidade do clima, do mercado e da política agrária, tornando-se instável e de alto risco, devendo ser bem planejada para garantir o seu sucesso. Entre todas as atividades econômicas, é a que mais depende das condições climáticas, sendo esta variável responsável por 60 a $70 \%$ da variabilidade final da produção (ORTOLANI;CAMARGO, 1987).

O clima é formado por vários elementos, como radiação solar, precipitação pluviométrica, temperatura do ar, umidade do ar, vento, pressão atmosférica, evaporação entre outros, onde é importante analisar a ação desses no ambiente. A variabilidade é um dos elementos mais conhecidos da dinâmica climática, e o impacto produzido por essa variabilidade, mesmo dentro do esperado pode ter reflexos significativos nas atividades humanas (OLIVEIRA et al., 2014).

Como em todo o Nordeste brasileiro, no território paraibano, as variações de temperatura do ar dependem mais de condições topográficas locais, que daquelas decorrentes de variações latitudinais (SALES; RAMOS, 2000).

O planejamento hídrico é a base para se dimensionar qualquer forma de manejo integrado dos recursos hídricos, assim, o balanço hídrico permite o conhecimento da necessidade e disponibilidade hídrica no solo ao longo do tempo. O balanço hídrico como unidade de gerenciamento, permite classificar o clima de uma região, realizar o zoneamento agroclimático e ambiental, o período de disponibilidade e necessidade hídrica no solo, além de favorecer ao gerenciamento integrado dos recursos hídricos (LIMA, 2009).

O balanço hídrico é uma primeira avaliação de uma região, que se determina a contabilização de água de uma determinada camada do solo, onde se define os períodos secos e úmidos de um determinado local (REICHARDT, 1990), identificando assim, as áreas onde as culturas podem ser exploradas com maior eficácia (BARRETO et al., 2009).

O termo ETo foi definido por Thornthwaite (1948), como a perda de água de uma extensa superfície vegetada, de porte rasteiro, em fase de desenvolvimento ativo e sem limitação hídrica. Segundo Pereira et al. (1997), a evapotranspiração é controlada pela disponibilidade de energia, pela demanda atmosférica e pelo suprimento de água do solo às plantas.

Evapotranspiração terrestre é um dos componentes mais importantes do ciclo hidrológico, afetando o equilíbrio de água na superfície da Terra. É também uma das variáveis meteorológicas que é muito aplicada à tomada de decisão em hidrologia, agroecologia, irrigação e outras áreas afins (FU et al., 2009; RODERICK et al., 2009). Resultados demonstram que a magnitude das tendências evapotranspiradas são fatores determinantes, que variam muito de região para região. Estudos adicionais sobre a evapotranspiração e registros em diferentes regiões dos países tropicais é sem dúvida útil para fornecer mais evidências e entendermos melhor a variabilidade $e$ a tendência da evapotranspiração global.

Outras formulações, assumem que, a superfície é extensa e continuamente saturada, omitindo os efeitos advectivos das variáveis, e conta apenas com o calor na vertical e fluxos de massas. Tais formulações são muitas 
vezes referidas, como área molhada potencial, de acordo com Morton (1983); Priestley e Taylor (1972) indicam que são mais adequados para ambientes de energia limitada. Modelos físicos, tais como, o método de Penman e as equações de Penman-Monteith, segundo Monteith (1981) e Penman (1948), são fisicamente derivados, exceto para os termos de resistência, e explicitamente incorporados a todas as variáveis de condução.

Para determinar às necessidades hídricas da planta, baseia-se no estudo da evapotranspiração (ETP), pois as mesmas dependem fundamentalmente das condições microclimáticas, tais como precipitação, velocidade do vento, temperatura e umidade relativa do ar, radiação solar; das características das plantas, entre elas, cultivar, estágio vegetativo, índice de área foliar, extensão e profundidade das raízes e atividade metabólica da planta; e ainda da água disponível no solo (FERREIRA, 1988).

Este trabalho objetiva calcular e mapear a evapotranspiração de referência (ETo) média mensal, anual e do trimestre seco e úmido para o Estado da Paraíba utilizando a metodologia de Thornthwaite

\section{2. ÁREA DE ESTUDO}

A área de estudo compreende o Estado da Paraíba, que está localizado na região Nordeste do Brasil, e apresenta uma área de $56.372 \mathrm{~km}^{2}$, que corresponde a $0,662 \%$ do território nacional. Seu posicionamento encontra-se entre os paralelos $6^{\circ} 02^{\prime} 12^{\prime \prime}$ e $8^{\circ} 19^{\prime} 18^{\prime \prime} \mathrm{S}$, e entre os meridianos de $34^{\circ} 45^{\prime}$ $54^{\prime \prime}$ e $38^{\circ} 45^{\prime} 45^{\prime \prime} \mathrm{W}$ (FRANCISCO, 2010).

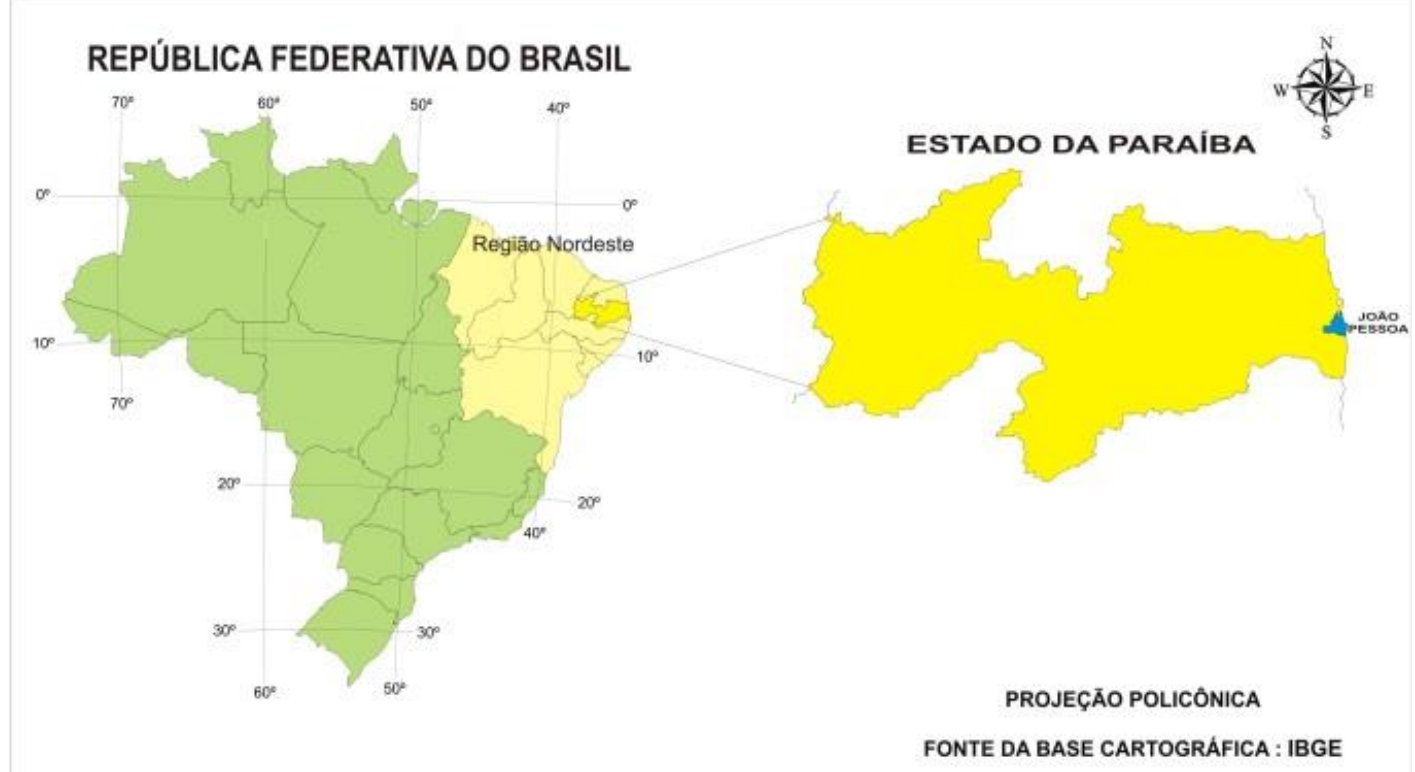

Figura 1 - Localização da área de estudo. Fonte: Francisco (2010).

Conforme Francisco (2010), relacionando-se clima e relevo define-se em três macrorregiões o Estado da Paraíba:

a) Planície Atlântica, englobando a encosta oriental do Planalto da Borborema - o terço leste do Estado, com o clima, segundo a classificação de 
Köppen, do tipo As' - Tropical Quente e Úmido com chuvas de outono-inverno. Nesta região, as chuvas são formadas pelas massas Atlânticas trazidas pelos ventos alísios de sudeste, e a altitude, na planície, inferior a $200 \mathrm{~m}$, pode ultrapassar a $600 \mathrm{~m}$, nos pontos mais elevados dos contrafortes do Planalto. A precipitação decresce do litoral $(1.800 \mathrm{~mm}$.ano-1) para o interior da região (600 mm.ano-1) devido, principalmente, a depressão do relevo, e torna a subir nos contrafortes do Planalto para $1.450 \mathrm{~mm}$.ano-1.

b) Planalto da Borborema - porção central do Estado, com clima do tipo Bsh - Semiárido quente, precipitação predominantemente abaixo de $600 \mathrm{~mm}$ ano-1, e temperatura mais baixa, devido ao efeito da altitude (400 a $700 \mathrm{~m}$ ). As chuvas da região sofrem influência das massas Atlânticas de sudeste e do norte;

c) Sertão - região que ocupa o terço oeste do Estado, formada pela depressão do rio Piranhas e seus contribuintes, com clima do tipo Bsh Semiárido quente, nas áreas mais baixas $(<300 \mathrm{~m})$, e $A w^{\prime}$ - Tropical Quente e Úmido com chuvas de verão-outono, nas áreas mais altas da depressão e em todos os contrafortes e topo do Planalto de Princesa ao sul, divisa com Pernambuco, e na área a oeste, com o Estado do Ceará.

Na metodologia elaborada os valores da evapotranspiração de referência foram estimados pelo método de cálculo do balanço hídrico segundo Thornthwaite e Mather (1948; 1955). Obtiveram-se os valores normais de evaporação real e evapotranspiração potencial além dos valores de excedente e deficiência hídrica. Tomou-se o valor de capacidade de água disponível no solo (CAD) de $100 \mathrm{~mm}$.

Os dados de precipitações climatológicas médias mensais e anuais foram adquiridos do banco de dados coletado pela Agência Executiva de Gestão das Águas do Estado da Paraíba (AESA), para o período de 102 anos entre 1912 a 2014. Os valores mensais e anuais de temperatura do ar, foram estimados pelo método das retas de regressões lineares múltiplas, utilizando-se do software Estima_T (CAVALCANTI et al., 2006). Após foi elaborada uma planilha eletrônica com os dados e preenchido os faltantes e depois de calculado as médias mensais, anuais e dos trimestres seco e úmido da evapotranspiração de referência. Utilizando o software Surfer 9.0 foi elaborada a estatística utilizando a krigeagem onde se confeccionou as cartas mensais, a carta anual e as do trimestre seco e úmido das referidas médias, e todos recortados utilizando-se o limite do Estado da Paraíba (IBGE, 2009).

Com os dados dessas séries, foi ajustado as equações pelo método dos mínimos quadrados, obtendo-se equações de regressão linear múltipla e testado pelo método estatístico:

$$
E(Y)=a_{0}+a_{1} X_{1}+a_{2} X_{2}+a_{3} X_{3}
$$

Onde: $\mathrm{Y}$ - temperatura mensal do ar (média, máxima ou mínima) ${ }^{\circ} \mathrm{C} ; \mathrm{X} 1, \mathrm{X} 2 \mathrm{e}$ X3 - latitude e longitude do local (minuto) e altitude (metro), respectivamente a0, a1, a2 e a3 - coeficientes da equação de regressão.

As equações de regressão linear múltipla para se estimar a temperatura do ar (máxima, mínima e média), foram obtidas a partir de dados de algumas estações climatológicas do INMET situadas no Estado. Por essas equações, as 
temperaturas máximas, mínimas e médias do ar foram estimadas com base na latitude, longitude e altitude locais.

\section{RESULTADOS E DISCUSSÃO}

Para alcançar os objetivos propostos foram consultados artigos $\mathrm{Na}$ Tabela 1, observam-se as variabilidades estatísticas dos parâmetros médios da temperatura do ar para o Estado da Paraíba, onde as oscilações da temperatura mínima mensal fluem entre 19,3 e $23,2^{\circ} \mathrm{C}$, com uma média anual de $21,7^{\circ} \mathrm{C}$. A temperatura máxima oscila entre 24,3 e $27,4^{\circ} \mathrm{C}$, e sua média é de $26,1^{\circ} \mathrm{C}$, e a temperatura média apresenta uma flutuação entre 22,2 e $25,6^{\circ} \mathrm{C}$, e sua média é de $24,2^{\circ} \mathrm{C}$.

Observa-se que a mediana tem um comportamento análogo ao da temperatura média, exceto para os meses de junho a novembro. As maiores flutuações do desvio padrão ocorrem nos meses de fevereiro, abril a setembro e dezembro. Estatisticamente os coeficientes de variâncias não têm índices expressivos de mudanças mensais, já no parâmetro variância as suas flutuações mensais apresentam valores com altas significâncias de ocorrências mensais.

Tabela 1 - Variabilidade estatística dos parâmetros da temperatura média do ar

\begin{tabular}{cccccccc}
\hline \multirow{2}{*}{ Mês } & \multicolumn{7}{c}{ Variabilidade dos parâmetros ( $\left.{ }^{\circ} \mathbf{C}\right)$} \\
\cline { 2 - 7 } & Mínimo & Mediana & Máxima & Média & $\begin{array}{c}\text { Desvio } \\
\text { Padrão }\end{array}$ & Variância & $\begin{array}{c}\text { Coef. de } \\
\text { Variação }\end{array}$ \\
\hline Janeiro & 23,2 & 25,7 & 27,4 & 25,6 & 1,05 & 1,10 & 0,04 \\
Fevereiro & 22,8 & 25,4 & 25,7 & 25,4 & 1,13 & 1,28 & 0,04 \\
Março & 22,6 & 25,1 & 27,1 & 25,0 & 1,08 & 1,16 & 0,04 \\
Abril & 21,9 & 24,6 & 26,5 & 24,5 & 1,15 & 1,34 & 0,04 \\
Maio & 21,0 & 23,7 & 25,7 & 23,6 & 1,22 & 1,49 & 0,05 \\
Junho & 19,8 & 22,8 & 24,8 & 22,7 & 1,32 & 1,75 & 0,02 \\
Julho & 19,3 & 22,4 & 24,3 & 22,2 & 1,34 & 1,81 & 0,06 \\
Agosto & 19,6 & 22,8 & 24,4 & 22,4 & 1,31 & 1,72 & 0,05 \\
Setembro & 21,1 & 23,9 & 25,3 & 23,5 & 1,14 & 1,30 & 0,04 \\
Outubro & 22,3 & 24,9 & 26,2 & 24,6 & 1,08 & 1,17 & 0,04 \\
Novembro & 22,9 & 25,9 & 26,8 & 25,2 & 1,05 & 1,12 & 0,04 \\
Dezembro & 23,0 & 25,5 & 27,4 & 25,5 & 1,12 & 1,25 & 0,04 \\
\hline Anual & 21,7 & 24,3 & 26,1 & 24,2 & 1,15 & 1,33 & 0,04 \\
\hline
\end{tabular}

Na Tabela 2, observa-se as variabilidades estatísticas dos parâmetros médios da precipitação para o Estado da Paraíba, onde as oscilações da precipitação mínima mensal fluem entre 0,1 a $60,77 \mathrm{~mm}$, com uma média anual de $332 \mathrm{~mm}$. A precipitação máxima oscila entre 38,5 a $369,4 \mathrm{~mm}$, e sua média é de $1.979,3 \mathrm{~mm}$, e a precipitação média apresenta uma flutuação entre 11,5 a $152,1 \mathrm{~mm}$ com média de $854,6 \mathrm{~mm}$. 
Tabela 2 - Variação da pluviosidade

\begin{tabular}{lccccccc}
\hline \multirow{1}{*}{ Mês } & \multicolumn{7}{c}{ Variação (mm) } \\
\cline { 2 - 7 } & Mínimo & Mediana & Máxima & Média & $\begin{array}{c}\text { Desvio } \\
\text { Padrão }\end{array}$ & Variância & $\begin{array}{c}\text { Coef. de } \\
\text { Variação }\end{array}$ \\
\hline Janeiro & 13,2 & 71,0 & 176,1 & 71,4 & 30,5 & 931,9 & 0,42 \\
Fevereiro & 33,2 & 94,6 & 191,9 & 99,8 & 38,5 & 1482,6 & 0,38 \\
Março & 40,5 & 145,5 & 272,9 & 152,1 & 51,8 & 2684,7 & 0,84 \\
Abril & 60,8 & 153,8 & 254,0 & 148,9 & 41,9 & 1762,5 & 0,28 \\
Maio & 36,5 & 89,9 & 305,1 & 103,1 & 53,3 & 2846,7 & 0,51 \\
Junho & 14,8 & 48,5 & 369,4 & 91,3 & 81,2 & 6592,9 & 0,88 \\
Julho & 1,8 & 32,0 & 298,0 & 73,1 & 69,6 & 4844,0 & 0,95 \\
Agosto & 1,0 & 13,0 & 179,2 & 39,5 & 43,9 & 1932,1 & 1,11 \\
Setembro & 0,1 & 7,1 & 103,4 & 20,3 & 22,5 & 506,2 & 1,10 \\
Outubro & 1,1 & 9,9 & 38,5 & 11,5 & 7,2 & 51,8 & 0,62 \\
Novembro & 0,6 & 13,7 & 48,1 & 14,2 & 8,5 & 72,4 & 0,59 \\
Dezembro & 6,8 & 26,1 & 93,9 & 29,3 & 13,3 & 176,3 & 0,45 \\
\hline Anual & 332 & 843,1 & 1979,3 & 854,6 & 315,66 & 99644,00 & 0,37 \\
\hline
\end{tabular}

Observa-se que a mediana apresentou um comportamento analógo ao da precipitação média, exceto para os meses de junho a outubro. As maiores flutuações do desvio padrão ocorrem nos meses de março a agosto, e estas flutuações, podem estar relacionadas, com os fatores provocadores e/ou inibidores dos índices pluviométricos intermunicipais. Estatisticamente os coefientes de variâncias não tem índices expressivos de mudanças mensais, já no parâmetro variância, as suas flutuações mensais apresentam valores com altas significâncias de ocorrências mensais.

Na Figura 2, observa-se a distribuição espacial da evapotranspiração de referência de janeiro a dezembro no Estado da Paraíba 

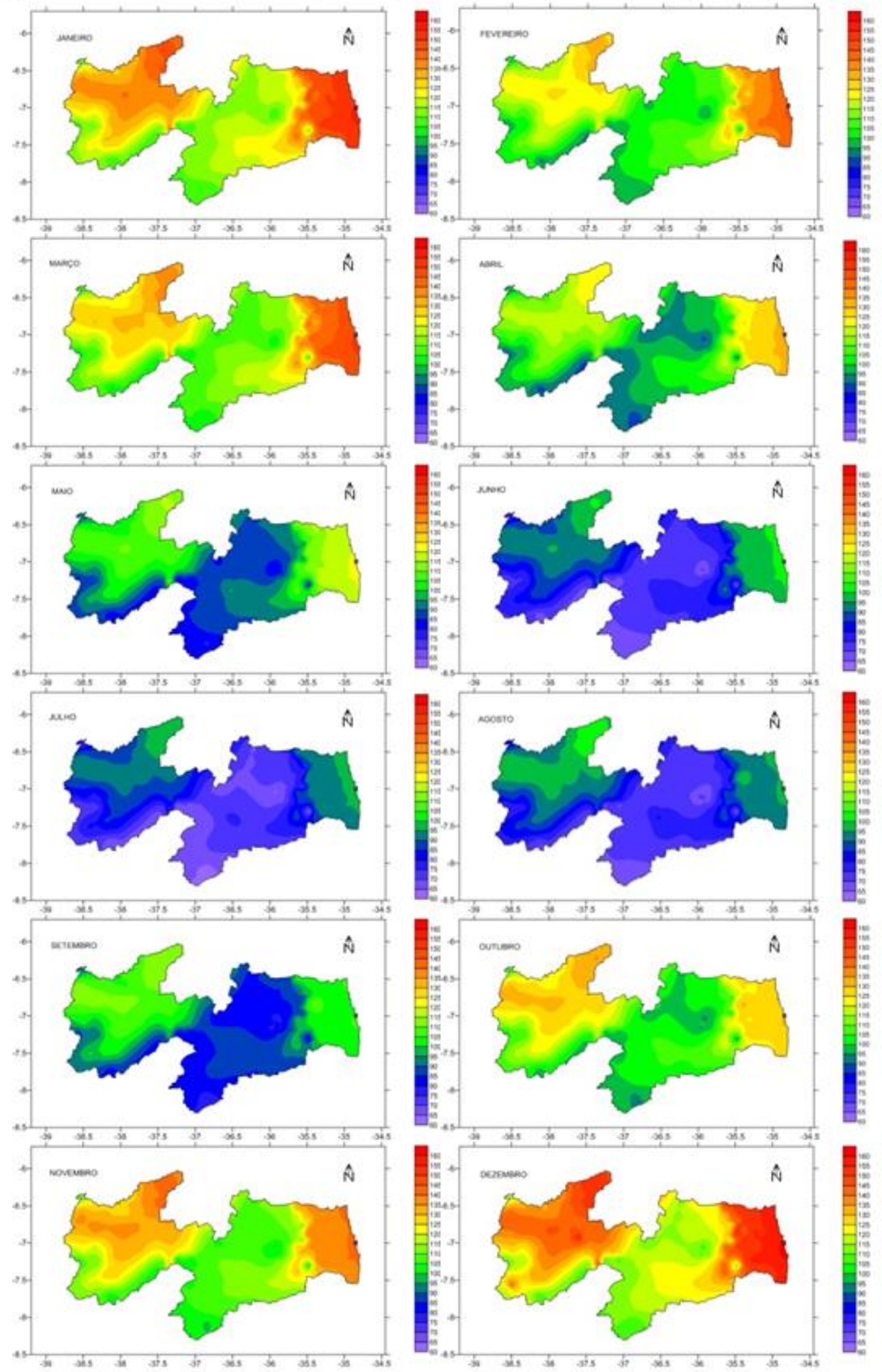

Figura 2 - Evapotranspiração potencial mensal. 
O Estado da Paraíba encontra-se dividido em seis mesorregiões, as quais apresentam grandes variabilidades climáticas entre elas, sendo classificadas como: Litoral, Brejo, Agreste, Cariri/Curimataú, Sertão e Alto Sertão Paraibano. O clima desta região é muito diversificado em função das condições topográficas e influencia os índices pluviométricos irregulares dentro do Estado. Outros fatores que influenciam na evapotranspiração da região são a vegetação e os tipos de solos muitos diversificados.

Verifica-se no mês de janeiro que, ocorre uma alta taxa evapotranspiratória no Litoral, Brejo e no Sertão, principalmente na divisa com o Rio Grande do Norte. Este índice pode estar atribuído a disponibilidade hídrica da região, além das condições de solo e vegetação locais. Nestas mesmas regiões, é possível verificar que, no mês de fevereiro a ETo começa a decrescer no sentido do Litoral e divisa com o Rio Grande do Norte.

Nas mesorregiões Agreste, Cariri/Curimataú e Alto Sertão, evidenciou uma tonalidade mais escura de janeiro a fevereiro, ou seja, houve um decréscimo na ETo, sendo que no mês de março ocorreu um pequeno aumento, voltando a diminuir no mês de abril e se estendendo até agosto. Observa-se que a evapotranspiração vai diminuindo no sentido da divisa com o Estado de Pernambuco, e avançando no sentido do Rio Grande do Norte e Litoral Paraibano. O baixo índice evapotranspirativo nos meses de maio a setembro, está associado à época de chuvas da área em estudo.

No mês de setembro, é possível verificar, que a ETo começa a aumentar e se intensificando até o mês de dezembro. Observa-se que, o índice evapotranspiratório é crescente de setembro a dezembro, avançando do Litoral e da divisa do Rio Grande do Norte no sentido da divisa com o Estado de Pernambuco. Observa-se através da Figura 2, que os seis meses de ETo mais intenso se estende de outubro a março, e os meses menos intensos, de abril a setembro. Verifica-se que, em todos os meses do ano, as mesorregiões do Litoral, Brejo e Sertão, demandam as maiores taxas evapotranspiratórias, e as menores taxas ocorrem no Agreste, Cariri/Curimataú e Alto Sertão.

Na evapotranspiração de referência anual (Figura 3), pode observar-se que, no Litoral ocorre uma média de ETo de aproximadamente $1.500 \mathrm{~mm}$.ano-1, já na região do Brejo, a evapotranspiração cai para $1.450 \mathrm{~mm}$.ano-1, diminuindo significativamente no Agreste, em torno de $1.150 \mathrm{~mm}$.ano-1, sendo as menores taxas advindas no Cariri/Curimataú e parte do Alto Sertão, entre 1.000 a 1.100 mm.ano-1, e tornado a crescer no Sertão e parte do Alto Sertão, intensificando no sentido ao Estado do Rio Grande do Norte. 


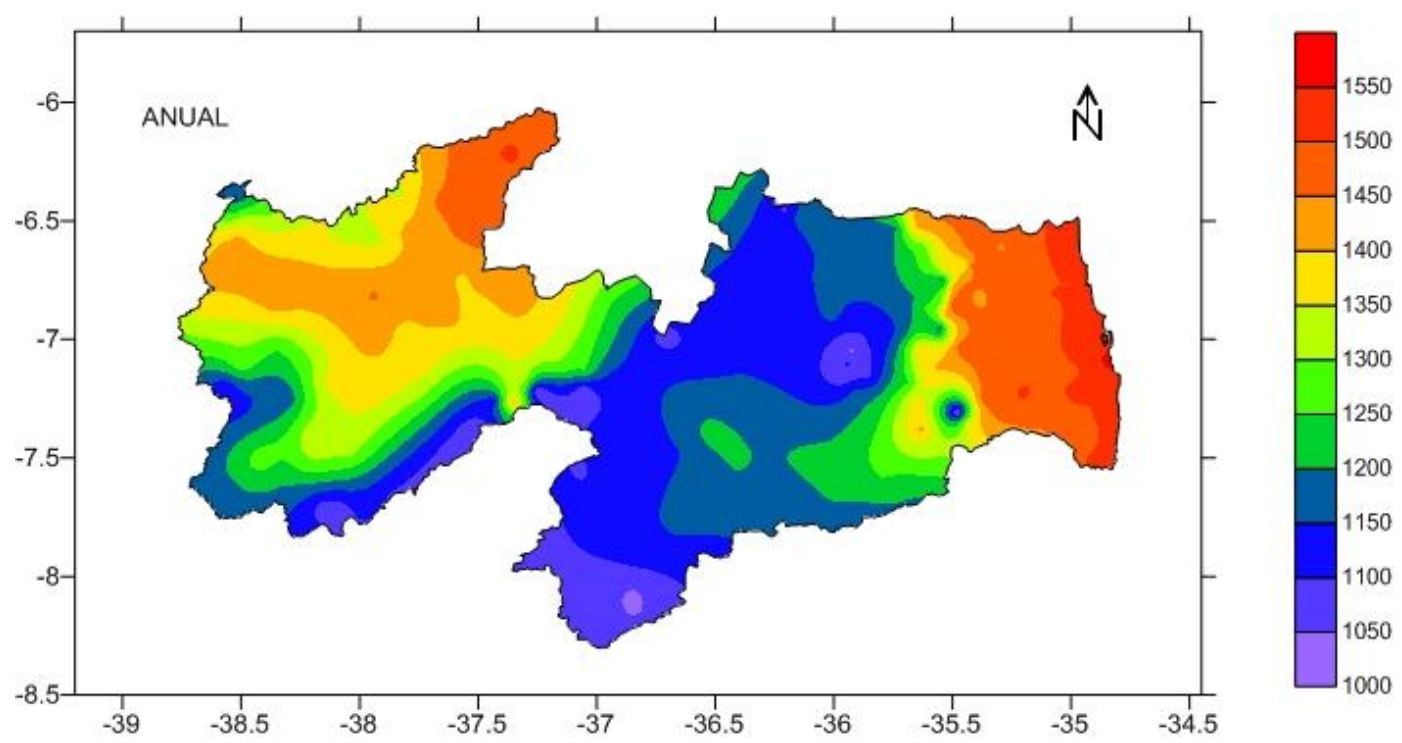

Figura 3 - Evapotranspiração potencial anual.

Na Tabela 3, observa-se a variabilidade estatística dos parâmetros médios da evapotranspiração potencial mensal e anual para o Estado da Paraíba, onde as oscilações da evapotranspiração mínima mensal fluem entre 62,75 a $105,79 \mathrm{~mm}$, com uma valor anual de $1.281,93 \mathrm{~mm}$. A evapotranspiração máxima oscila entre 99,09 a $162,76 \mathrm{~mm}$, com valor anual de $1.556,58 \mathrm{~mm}$, e a evapotranspiração média apresenta uma flutuação entre 81,43 a 132,18mm, com valor anual de $1.288,8 \mathrm{~mm}$.

Tabela 3 - Variação da evapotranspiração potencial mensal e anual

\begin{tabular}{lccccccc}
\hline \multirow{2}{*}{ Mês } & \multicolumn{7}{c}{ Variação (mm) } \\
\cline { 2 - 7 } & Mínimo & Mediana & Máxima & Média & $\begin{array}{c}\text { Desvio } \\
\text { Padrão }\end{array}$ & Variância & $\begin{array}{c}\text { Coef. de } \\
\text { Variação }\end{array}$ \\
\hline Janeiro & 104,08 & 127,89 & 157,60 & 128,60 & 14,23 & 202,59 & 0,11 \\
Fevereiro & 92,76 & 115,36 & 146,72 & 115,47 & 14,13 & 199,77 & 0,12 \\
Março & 99,11 & 121,29 & 152,16 & 122,59 & 13,87 & 192,44 & 0,11 \\
Abril & 87,36 & 108,02 & 134,63 & 108,39 & 12,71 & 161,63 & 0,11 \\
Maio & 79,39 & 98,48 & 123,22 & 99,66 & 11,85 & 140,64 & 0,11 \\
Junho & 65,06 & 83,44 & 103,49 & 84,04 & 10,54 & 111,28 & 0,12 \\
Julho & 62,75 & 81,61 & 99,09 & 81,43 & 10,17 & 103,44 & 0,12 \\
Agosto & 64,75 & 85,66 & 103,15 & 84,01 & 10,21 & 104,35 & 0,12 \\
Setembro & 76,03 & 96,88 & 114,81 & 95,49 & 10,17 & 103,62 & 0,10 \\
Outubro & 91,64 & 116,79 & 135,34 & 114,36 & 11,97 & 143,37 & 0,10 \\
Novembro & 98,68 & 122,01 & 143,42 & 121,52 & 12,89 & 166,34 & 0,10 \\
Dezembro & 105,79 & 132,32 & 162,76 & 132,18 & 15,58 & 243,00 & 0,11 \\
\hline Anual & 1038,61 & 1281,93 & 1556,58 & 1288,80 & 144,78 & 20962,7 & 0,11 \\
\hline
\end{tabular}

A Figura 4 representa o trimestre de menor evapotranspiração, que corresponde aos meses de junho, julho e agosto. A variabilidade do trimestre de menor evapotranspiração oscila entre 64,5 a $145,7 \mathrm{~mm}$, entre os municípios que cobrem o Estado da Paraíba, com uma média de $83,2 \mathrm{~mm}$. Observa-se que na área do Cariri setentrional e ocidental, ocorrem os menores índices 
evaporativos. Destaca-se áreas de menor ocorrência na divisa do Estado de Pernambuco. Nas regiões do Sertão, Alto Sertão, Litoral, e em parte da região do Agreste, os valores da evapotranspiração de referência fluem entre 90 a $115 \mathrm{~mm}$.
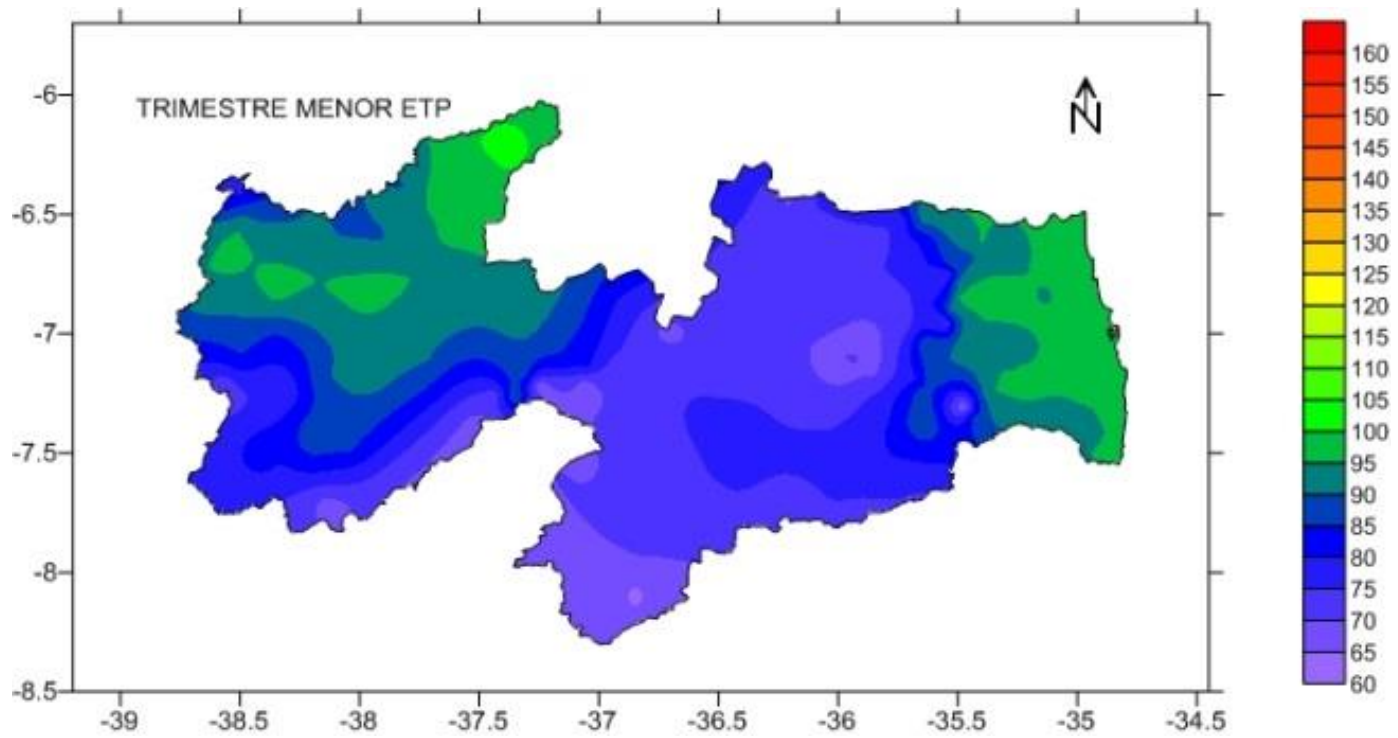

Figura 4 - Trimestre de menor evapotranspiração potencial.

Na Figura 5, observa-se a variabilidade espacial dos valores evaporativos ocorridos no trimestre de maior evapotranspiração, que corresponde aos meses de outubro, novembro e dezembro, com flutuações intermunicipais de 99,2 a 145,7mm, ocorrendo na área Litorânea e no setor norte do Sertão. Os menores índices evaporativos ocorrem na faixa do Cariri/Curimatau, e na divisa com o Estado de Pernambuco, devido aos efeitos dos ventos e do relevo. Na região do Brejo, Agrestre e Alto Sertão, têm-se flutuações intermediárias entre as demais áreas.
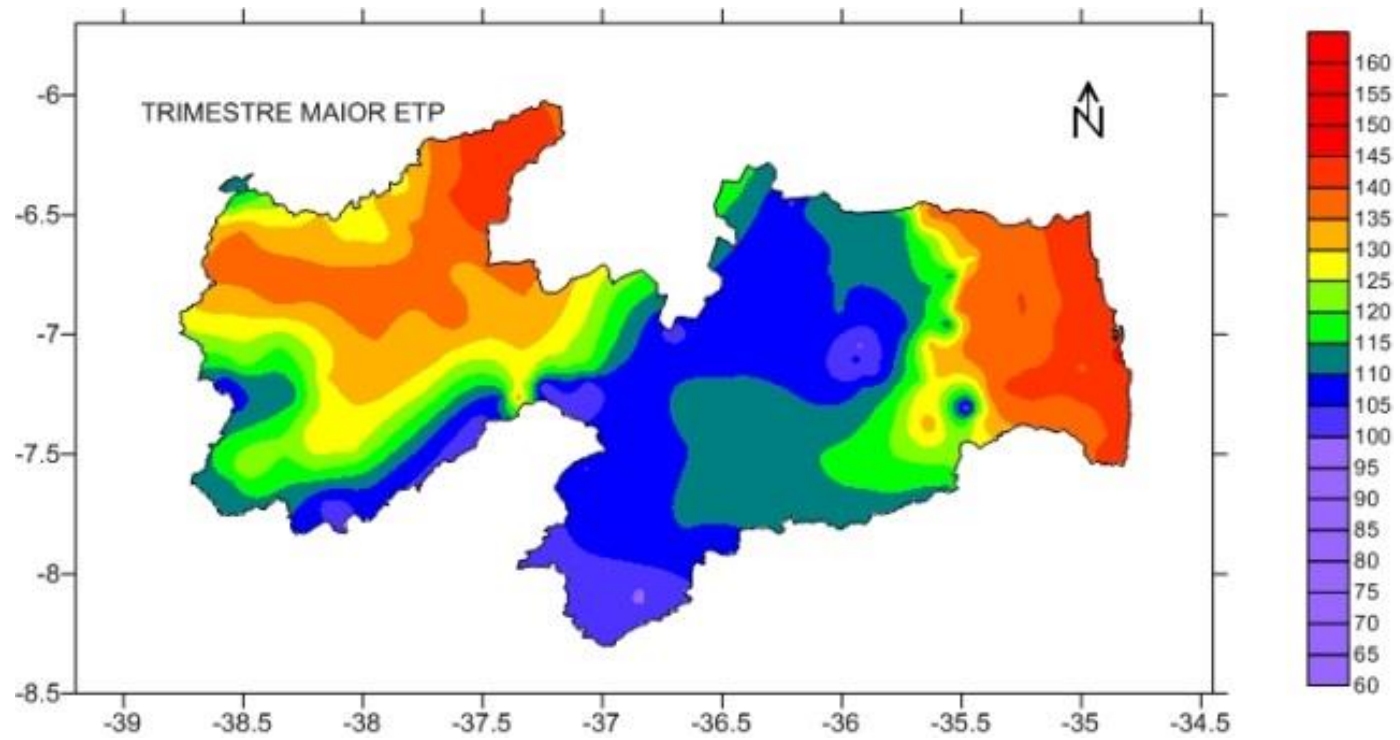

Figura 5 - Trimestre de maior evapotranspiração potencial. 
Matos et al. (2014), constataram em estudo da aptidão climática através do balanço hídrico conforme Thornthwaite e Mather (1948, 1955), que a evapotranspiração, se comportou de forma semelhante a precipitação pluvial, e quando houve um maior índice de precipitação, ocorreu também aumento nas taxas evapotranspiratórias.

Estes resultados estão de acordo com vários estudos realizados para o semiárido nordestino, conforme (GUEDES FILHO et al., 2011; MATOS et al., 2014).

Pereira et al. (2012), relatam que a mesorregião do Sertão Paraibano, apresenta uma maior taxa de água evapotranspirada, quando comparada as outras regiões. Os mesmos, descrevem que, as mesorregiões do Sertão, Borborema e Agreste, possuem um baixo índice de precipitação, quando comparada a alta evapotranspiração anual ocorrida, sendo o maior volume pluviométrico advindo da região Litoral do Estado.

Os métodos de estimativa da evapotranspiração, comumente evidenciam adequado desempenho para diferentes regiões e condições climáticas, quando baseados em princípios físicos próprios dos processos de evaporação (BERLATO; MOLION, 1981).

\section{CONCLUSÕES}

As estimativas de ETo mensais para o Estado da Paraíba, apresentam dependência da localização geográfica (latitude e longitude), sobretudo da topografia local (altitude).

Os resultados da ETo estão de acordo com vários estudos realizados para a região semiárida do Nordeste Brasileiro.

Esta tendência, é um reflexo da variação espacial da temperatura média do ar mensal na área de estudo.

Em todos os meses do ano, as regiões do Litoral, Brejo e Sertão, demandam as maiores taxas evapotranspiratórias, e as menores taxas ocorrem no Agreste, Cariri/Curimataú e Alto Sertão.

AGRADECIMENTOS: Ao CNPq/Fapesq pela concessão de bolsa de pesquisa ao primeiro autor

\section{REFERÊNCIAS BIBLIOGRÁFICAS}

BARRETO, P. N.; SILVA R. B. C.; SOUZA, W. S.; COSTA, G. B.; NUNES, H. G. G. C.; SOUSA, B. S. B. Análise do balanço hídrico durante eventos extremos para áreas de floresta tropical de terra firme da Amazônia Oriental. In: Congresso Brasileiro de Agrometeorologia, 16, Belo Horizonte, 2009.

BERLATO, M. A.; MOLION, L. C. B. Evaporação e Evapotranspiração. Porto Alegre, IPAGRO: Secretaria de Agricultura, RS. 1981. 95p. (Boletim Técnico, 7). 
CAVALCANTI, E. P.; SILVA, V. de P. R.; SOUSA, F. de A. S. Programa computacional para a estimativa da temperatura do ar para a Região Nordeste do Brasil. Revista Brasileira de Engenharia Agrícola e Ambiental, v.10, n.1, p.140-147, 2006.

FERREIRA, E. J. Determinação da evapotranspiração e do coeficiente de cultura (Kc) para a aveia preta (Avena strigosa, Sckereb) irrigada. 70f. Dissertação (Mestrado em Agronomia). Universidade Federal de Viçosa, Viçosa - MG, 1988.

FRANCISCO, P. R. M. Classificação e mapeamento das terras para mecanização do Estado da Paraíba utilizando sistemas de informações geográficas. 122f. Dissertação (Mestrado em Manejo de Solo e Água). Centro de Ciências Agrárias. Universidade Federal da Paraíba. Areia, 2010.

FU, G.; CHARLES, S. P.; YU, J. A critical overview of pan evaporation trends over the last 50 years. Clim. Change, n.97, p.193-214, 2009.

GUEDES FILHO, D. H.; SANTOS JÚNIOR, J. A.; COSTA FILHO, J. F.; FRANCISCO, P. R. M.; CAMPOS, V. B. Estimativa da evapotranspiração de referência para a cidade de Areia, Paraíba. Revista Brasileira de Agricultura Irrigada, v. 5, n. 1, p. 37-47, 2011.

IBGE. Instituto Brasileiro de Geografia e Estatística. 2009. Disponível em http://www.ibge.gov.br. Acesso em 12 de março de 2011.

LIMA, F. B.; SANTOS, G. O. Balanço hídrico-espacial da cultura para o uso e ocupação atual da bacia hidrográfica do Ribeirão Santa Rita, Noroeste do Estado de São Paulo. 89p. Monografia. Fundação Educacional de Fernandópolis, Fernandópolis - SP, 2009.

MATOS, R. M.; SILVA, J. A. S.; MEDEIROS, R. M. Aptidão climática para a cultura do feijão caupi do município de Barbalha - CE. Revista Brasileira de Agricultura Irrigada, v.8, n.6, p.422-431, 2014.

MONTEITH, J. L. Evaporation and surface temperature. Quarterly Journal of the Royal Meteorological Society, n.107, 451, p.1-27, 1981.

MORTON, F. I. Operational estimates of areal evapo-transpiration and their significance to the science and practice of hydrology. Journal of Hydrology, n.66, v.1-4, p.1-76, 1983.

OLIVEIRA, R. C. S.; MEDEIROS, R. M. DE; COSTA NETO, F. DE A.; GOMES FILHO, M. F. Estudo das oscilações da temperatura máxima do ar e precipitação em Lagoa Seca-PB visando mudanças climáticas. In: VI Workshop de Mudanças Climáticas e Recursos Hídricos do Estado de Pernambuco e III Workshop Internacional sobre Mudanças Climáticas e Biodiversidade, Recife, 2014.

ORTOLANI, A. A.; CAMARGO, M. B. P. Influência dos fatores climáticos na produção. In: Castro, P. R. C.; Ferreira, S. O.; Yamada, T. Ecofisiologia da produção agrícola. Associação Brasileira para Pesquisa da Potássio e do Fosfato, 1987, p.71-81.

PENMAN, H. L. Natural evaporation from open water, bare soil and grass. Proceedings of the Royal Society of London, n.193, p.120-145, 1948. 
PEREIRA, A. R.; VILLA NOVA, N. A.; SEDIYAMA, G. C. Estimativa de evapotranspiração. Piracicaba: FEALQ, 1997. p.41-99.

PEREIRA, M. C. A.; MELO, D. F.; MELÓ, R. G. C.; SILVA, R. F. B.; FARIAS, S. A. R. Mesorregiões da Paraíba e suas necessidades de captação de água de chuva. In: SIMPÓSIO BRASILEIRO DE CAPTAÇÃO E MANEJO DE ÁGUA DE CHUVA, 8., 2012, Campina Grande. Anais... Campina Grande: FIEP, 2012. p. 01-06.

PRIESTLEY, C. H. B.; TAYLOR, R. J. On the assessment of surface heat flux and evaporation using large-scale parameters. Monthly Weather Review, n.100, v.2, p.81-92, 1972.

REICHARDT, K. A água em sistemas agrícolas. Barueri -SP: Ed. Manole, 1990.

RODERICK, M. L.; HOBBINS, M. T.; FARQUHAR, G. D. Pan evaporation trends and the terrestrial water balance. I. Principles and observations. Geogr. Compass, n.3, v.2, p.746-760, 2009.

SALES, M. C. L., RAMOS, V. M. Caracterização ambiental das áreas sob influência do reservatório de Bocaina (PI) com base na compartimentação geomorfológica. In: Carta CEPRO, Teresina, 2000, v.18, n.1, p.149-161.

THORNTHWAITE, C. W. An approach toward a rational classification of climate. Geogr. Rev., v.38, p.55-94, 1948.

THORNTHWAITE, C. W.; MATHER, J. R. The water balance. Publications in Climatology. New Jersey: Drexel Institute of Technology, 104p. 1955. 